\title{
The model of specialists training system for high-tech industries
}

\author{
Mikhail Solovyev ${ }^{1,}{ }^{*}$, Kseniya Mertins ${ }^{1}$, and Anton Shagdyrov ${ }^{1}$ \\ ${ }^{1}$ National Research Tomsk Polytechnic University, 634050 Tomsk, Russia
}

\begin{abstract}
The article reviews the world experience of the specialist training model for high-tech industries. The focus is made on the approach to organization of training to help students develop enterprisetechnological skills implemented in National Research Tomsk Polytechnic University. The model considers the strategy of scientific and technological development adopted in the Russian Federation and the need of high-tech industries to improve the quality of educational and training programs and training of the personnel to meet the demand of today's environment who are ready to face future challenges and to establish new markets, and creates the conditions for development of entrepreneurial and technological competences.
\end{abstract}

\section{Introduction}

In the rapidly changing world of technology, the key determinants of the enterprise competitiveness are ongoing efforts to generate new knowledge and readiness for introduction of technological and organizational innovations (rapid changes in technology and financial chains, production cycle restructuring, etc.). This puts forward new requirements for staffing of industries. This is the development trend of modern world universities. Research universities are gradually transformed into (Univ. 2.0) entrepreneurial universities (Univ. 3.0), and then into universities that create new markets and build market infrastructures [1] (Univ. 4.0). In the "Strategy of scientific and technological development» of the Russian Federation it is required introduction of technologies, products and services to the modern market: digital manufacturing technologies, robotic systems, new materials and construction methods, big data processing, clean energy, and others [2]. The Strategy obliges the universities to trans form into open educational and scientific-technological platforms for development of engineering and training of tech entrepreneurs.

\section{Requirements of modern high-tech industries}

There are three main types of specialists in the field of engineering: engineers who operate technological equipment; engineers who implement technology and development; engineers who develop new technologies and equipment.

*Corresponding author: solo@tpu.ru 
The research identified a number of basic requirements for future employees of high tech industries, the engineers of all the three types [3]:

- profound scientific, mathematical and engineering knowledge;

- critical awareness of the forefront in the professional field, the ability to apply new and emerging technologies in the field of specialization;

- innovative approach to develop new original ideas and solutions of engineering problems (to be able to identify, properly formulate and solve practical engineering problems, including implementation of digital modeling as the basis for design and engineering); detailed understanding of the scientific principles of professional activity, the ability to plan and carry out research;

- an ability to plan the product life cycle and willingness to manage the project from concept development on down to launch on the market.

Many years' experience and a variety of approaches to training of specialists in the leading Russian universities allow effective preparation of specialists to meet these requirements [4].

A new market demands sharp reduction in the time between knowledge acquisition and creation of technologies based on this knowledge pose additional and critical requirements that apply to employees of high-tech companies: critical thinking, emotional intelligence, change management, the ability to manage people and interact with them, teamwork, etc. [5]. These competences are crucially important for of specialists of 2 nd and 3rd types. The educational programs of universities must respond to changes in these requirements.

\section{Experience in training engineers of today}

Moscow Polytechnic University. Large-scale implementation of new educational programs and technologies: STEM education enabling to help students bridge the gap between educational objectives and activities of a scientist and an engineer. Master's degree program in production-engineering (programs are based on promising R\&D-projects concerning topical areas of engineering and IT science, implemented to the order or in cooperation with leading IT companies [6], in accordance with STI [7] and Horizon 2020, and others. A compulsory course "Project Activities" involves 4 to 12 people, specialis ing in different areas (1st year), within which various engineering projects are performed, including those carried out to employers' orders. The projects are presented to technical commis sions [8].

Peter the Great St. Petersburg Polytechnic University (SPBPU). Implementation of modern approaches to training of engineers on the basis at the Institute for Advanced Manufacturing Technologies (substantive modernization of the mathematical foundation for engineers, practice-based learning technology in the framework of applied projects, creation of Digital Factory and others) [9].

Tomsk Polytechnic University. Preparation of the three major types of engineering specialists in TPU covers a wide range of training areas. The main components of the system for training engineering specialists (Figure 1) to meet the requirements of employers include:

- research and education centers and university laboratories (annual revenues from $\mathrm{R} \& \mathrm{D}$ is over 1.8 billion rubles);

- cooperation with enterprises (involvement of employers in the design of the basic educational program (BEP), study of specific modules focused on professionally-oriented practices, development of the project work themes, assessment of students' learning outcomes);

- increased amount of practices: 27 credits (18 weeks for 1-4 year); 
- use of resources of other educational organizations (SSMU and others) to acquire unique competencies required in each field;

- implementation of the module "Preparation for an integrated engineering process" aimed to provide, the 1st and 2nd year students with a clear view of the future professional activity, to form the skills required for the project and team work, and to involve students in engineering practice through solving simple problems of design, modeling and analysis in the field of technology;

- 3rd and 4th year students deal with more complex projects to the order of enterprises within the educational and research work, and complex projects in professional disciplines aimed to prepare students for the graduate qualification work [8] (Figure 2).

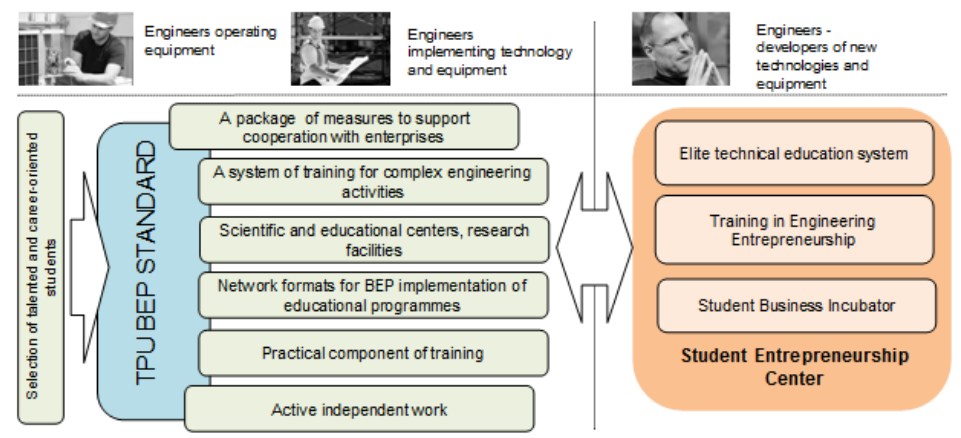

Fig. 1. Training of the personnel in TPU.
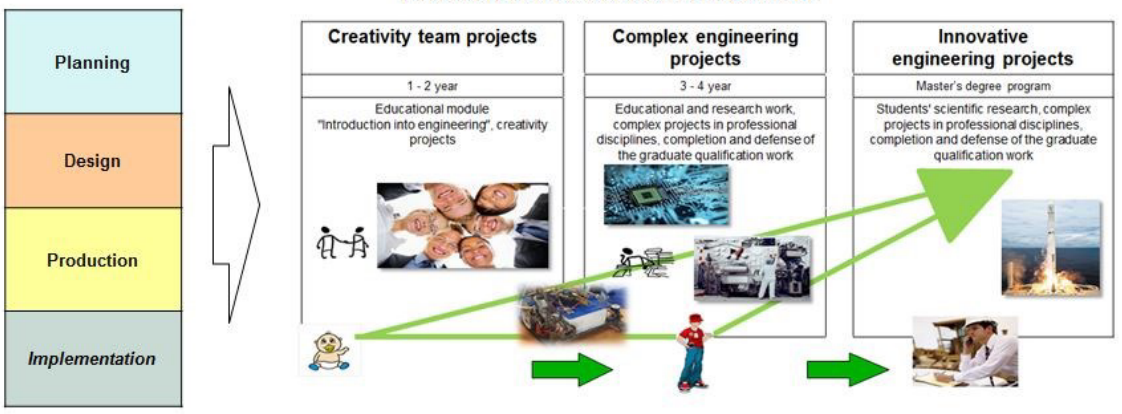

Fig. 2. System of training students for complex engineering activity.

To prepare specialists of the third type (capable of developing new technologies and equipment), an individual program has been implemented in TPU within the framework of elite engineering education since 2004 [10]. The program is developed for a group of selected students (about $10 \%$ of the total number of students). Similar educational programs are utilized in the world's leading universities: MIT, OLIN, University of Toronto and others. The elite engineering education program enables development of competences related to fundamental and professional knowledge, innovation, entrepreneurship and leadership in graduate students.

In addition, all students of undergraduate and specialty levels are enrolled in the discipline "Engineering entrepreneurship" (training in basics of entrepreneurship, acquiring skills in searching business opportunities and resources, new market niches, etc.). Moreover, competitions, trainings and business schools are held in the Student Business Incubator and the Department of Engineering Entrepreneurship. 


\section{Model of training specialists for high-tech industries}

Based on the experience of Russian and foreign universities and needs of modern high-tech industries, a system of training specialists has been proposed to ensure the following activities (Figure 3):

- conduction of basic and applied research; active work with potential applicants of all levels of educational background (information events for career guidance and engineering promotion, involvement of talented students);

- students' project (including independent) work on real practice-oriented projects, a large proportion of practices within the scope of the program;

- implementation of a wide range of students' activities [11];

- entrepreneurship development system for students (special educational modules, trainings, resource support).

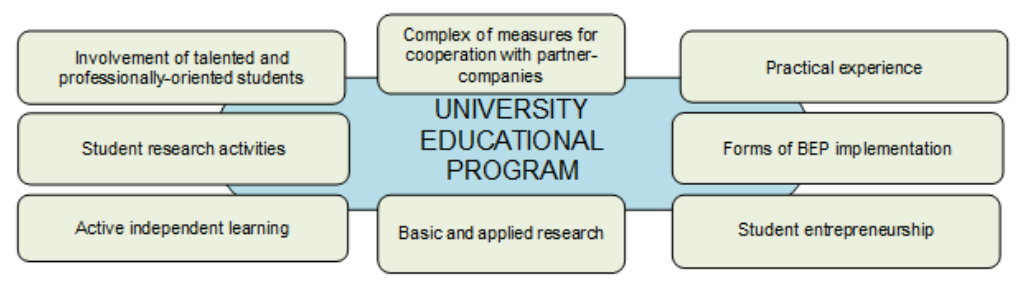

Fig. 3. Model of training specialists for high-tech industries.

The development of students' activity is crucial for acquisition of entrepreneurial competencies: independent learning, project work, students' entrepreneurship infrastructure (co-working centers, trainings, internal and external grants, acceleration programs, etc.). Implementation of the proposed principles and approaches will enable a modern university to create educational programs that are competitive in the global market of educational services [12].

\section{Conclusion}

The model of training sought-after specialists for high-tech industries (including those for the space industry) has been developed based on the strategy of science and technology development of the Russian Federation and the experience gained by Russian and foreign universities.

\section{References}

1. Project 5-100, URL: http://5top100.com/about/more-about/

2. Strategy of scientific and technological development of the Russian Federation, URL: http://sntr-rf.ru/

3. N. Daneikina, Y. Daneykin, INTED2016 Proceedings, 3565 (2016)

4. V. Ivanova, K. Mertins, et al, Mat. Web of Conf. 48, 06002 (2016)

5. Speech of German Gref at the III Congress "Innovative practice: science plus business". URL: http://scienceplusbusiness .ru/congress (2016)

6. A.Ju. Filippovich, Ju.N. Filippovich, PREPOD. XXI VEK 3, 28 (2016)

7. National Technology Initiative, URL: $\underline{\text { https://asi.ru/nti/ }}$ 
8. M. A. Soloviev, et al. Mat. Web of Conf. 48, 06001 (2016)

9. A. Borovkov, Digital Factor of Advanced Manufacturing Technologies Institute of SPBPU. URL: http://fea.ru/news/6387 (2016)

10. O.M. Zamyatina, et al, WSJ 27 (ELELC), 434 (2013)

11. A. Shvindt1, I. Nikanorov, Mat. Web of Conf. (2017) (to be published)

12. G.A. Voronova, M.A. Soloviev, Molodoy Ucheniy, 10, 589 (2015) 